\title{
Experimental and modeling study of a membrane filtration process using ceramic membranes to increase retroviral pseudotype vector titer
}

\section{Authors:}

Dirk Nehring, Roberto Gonzalez*, Peter Czermak, Ralf Pörtner**

University of Applied Sciences Giessen-Friedberg, Department of Biotechnology, Wiesenstr. 14, 35390 Giessen, Germany

*CECYEN, University of Matanzas, Matanzas 44740, Cuba

**Technische University Hamburg-Harburg, Department of Biotechnology I, Denickestraße 15, 21071 Hamburg, Germany

\section{Abstract:}

The ability of commercial ceramic asymmetric ultrafiltration membranes with a cut-off of 10 and $20 \mathrm{kDa}$ to purify retroviral pseudotype vectors derived from the murine leukemia virus carrying the HIV-1 envelop protein MLV(HIV-1) was studied. To optimize the filtration process a mathematical model of batch wise vector purification was set up. 745 to $1794 \mathrm{ml}$ batches of supernatant containing a maximum of $3.2 \times 10^{5}$ colony forming units per $\mathrm{ml}(\mathrm{cfu} / \mathrm{ml})$ was produced in a $200 \mathrm{ml}$ fixed bed reactor. By cross flow filtration the vector concentration was increased 10-fold with an average recovery of $84.5 \pm 4.5 \%$ of the initial infective capacity. Furthermore membrane layer formation and temperature dependent decay of transduction competent vector particles (decay) was included in the mathematical model. A maximal end point titer of $4.1 \times 10^{6} \mathrm{cfu} / \mathrm{ml}$ was predicted by the model and confirmed reasonably well by experimental data. Transmembrane flow of batch filtration was predicted by solving a set of related differential equations. Our modeling allows scale-up of the process and prediction of process performance including specific issues such as vector degradation.

Keywords: retrovirus, gene therapy, purification, membrane filtration, layer formation, mathematical model, ceramic membrane

This paper published as: Dirk Nehring, Roberto Gonzalez, Ralf Pörtner, Peter Czermak (2004). "Experimental and modeling study of a membrane filtration process using ceramic membranes to increase retroviral pseudotype vector titer." Journal of Membrane Science vol. 237 issues $1-2$ pages $25-38$

\section{Introduction}

Recombinant retroviruses such as the murine leukemia virus (MLV) have been used in many clinical trials since the last decade [1]. While some of the current production tools and strategies of pharmaceutical vaccines and recombinant protein production are applicable for purification and concentration of viral vectors, the complexity and instability of retroviral pseudotype vectors appear to require advanced technologies. Optimization of bioreactors and production processes should result in the production of large quantities of retroviral stocks while avoiding loss of viral activity. Recently, it has been reported that due to fast 
degradation rates of retroviral particles and low cell productivity the concentration does not reach the appropriate level for successful application in gene therapy [1] [2] [4] [11] [18].

To increase the vector titer laboratory scale purification methods such as density centrifugation and gel permeation chromatography have been implemented [1] [2]. Some studies have shown however that the recovery of the colony-forming vectors after density centrifugation was less than $1 \%$ [3] [14]. Taking into consideration that one therapeutic dose might typically require $10^{10}$ to $10^{11}$ colony forming units per $\mathrm{ml}(\mathrm{cfu} / \mathrm{ml})$ in an infusion product [4] [13] [18] the volume to be processed will need to exceed 1001 . Density ultra centrifugation is an impracticable for processing volumes of theis magnitude due to the load capacity of the centrifuges. Compared to ultra centrifugation cross flow filtration can process larger quantities of supernatant with a higher yield of active pseudotype vectors over the same time period. However the principles of vector filtration are influenced by medium contents and the vector decay.

Other studies show promising results by using dead end filtration. Reports of tangential and dead end microfiltration or ultrafiltration using polysulfone or cellulose membranes have shown recovery of up to $90 \%$ of the colony forming vector particles in the retentate [5] [10] [11].

Kuiper et al. diafiltered 21 batches ,22-40 1 in volume, of a replication incompetent Moloney murine leukaemia virus (MoMuLV) using a $0.3 \mathrm{~m}^{2}, 100 \mathrm{kDa}$ molecular weight cut-off ultrafiltration module [10]. Their paper describes a combined (dilution -is this correct?) and filtration method to achieveapproximately 100-fold concentration. Five batches of transduction competent virus (average titer $7.5 \pm 3.0 \times 10^{5} \mathrm{cfu} / \mathrm{ml}$ ) wereconcentrated up to $4.5 \pm 0.8 \times 10^{7} \mathrm{cfu} / \mathrm{ml}$ with a mean recovery of transduction competent virus $65 \pm 18 \%$. Lee et al. used a stirred ultrafiltration unit of $100 \mathrm{kDa}$ to increase the active vector concentration by 18 -fold [11]. However, in both studies the influence of technical parameters on the filtration process itself has not been investigated and no mathematical model was introduced.

Cruz et. al. performed retroviral vector filtration with a cellulose membrane in a stirred cell at a constant operating pressure of 3 bar and a stirring rate of 60 to $170 \mathrm{rpm}$ [5]. To determine the filtration process Cruz et al. applied a complete blocking model published by Hermia in the early 1980s [7]. Although the model, described the experimental data for constant transmembrane pressure and stirring rate well, (correlation of 0.993), pressure variationfrom 3 to 4 bar was not adequately described by the model. In fact, pressure variatiosn could only be accounted for by changing the complete blocking constant for $23 \%$ to $38 \%$. This indicates that the model is not suitable to predicted different constant transmembrane pressure set ups. For optimisation and scale up of retroviral vector filtration, transmembrane pressure is a parameter that should be considered in the mathematical model, with sufficeint accuracy. Furthermore the model doesn't take membrane properties and temperature dependent vector decay into consideration [5]. For process scale up e.g. 100 to $1000 \mathrm{l}$, more efficient filtration simulation tools that include transmembrane pressure as well as vector decay are required.

In this article we introduce a mathematical model that includes the decay of active vector particles and the transmembrane flow of the filtration process as a function of pressure and protein content in the medium. Experimental data of retroviral vector cross flow filtration were fitted to the model and compared to standard microfiltration model approaches such as complete blocking, standard blocking, intermediate blocking and cake filtration model [7]. 
We focuse on the maximization of vector concentration by applying the model to cross flow filtration of vector containing supernatant. We considered the mechanism of microfiltration to be only the first step towards complete downstream processing and purification. By obtaining the necessary coefficients from simple vector free experiments, ouri model offers the possibility to compare different membranes.

The impact of this work arises from the fact that temperature dependant vector decay results in a loss of active vector particles. To increase vector recovery, optimal filtration conditions and process scale up may be determined by empirical filtration models that take at least transmembrane pressure and membrane resistances into consideration.

\section{Material and Methods}

\section{Cell line and media}

The retroviral packaging cell line TELCeB6/pTr712-K52S (K52S) was derived from the env-negative MLV packging cell line TELCeB6 by transfection of the HIV-1 env-gene with the plasmids pTr712 and was donated by Prof. Cichutek (Paul Ehrlich Institute, Langen, Germany) [18]. It produces permanent MLV(HIV-1)-vector particles containing the transfer vector MFGlnslacZ. In addition the selection marker $b s r$ was implanted to gain blasticidin resistance. The cell line K52S produces a maximum vector titer of $2 \times 10^{5} \mathrm{cfu} / \mathrm{ml}$ in static cell culture flasks. K52S cells were grown in Dulbecco's Modified Eagle's medium (DMEM) (Gibco/BRL, Eggenstein, Germany) supplemented with 5\% fetal calf serum (FCS) (PAA, Germany), 800mg/l neomycin sulphate (Roth, Giessen, Germany), 5mg/l blasticidin S (ICN -Flow, Meckenheim, Germany) and 2mM glutamine (ICN -Flow, Meckenheim, Germany) contents. All target cells were cultured in the same medium but without blasticidin.

\section{Analysis}

To calculate the vector titer an X-Gal staining procedure was applied. Endpoint titration of pseudotype vector stocks was performed using various dilutions with a total volume of $1 \mathrm{ml}$ to infect adherent $\mathrm{CD} 4^{+}$HELA cells. Adherent target cells were grown at a initial density of $1.6 \times 10^{4}$ cells per 24-well culture dish (Nunc, Wiesbaden, Germany) 24 hours prior to transduction. All target cells were exposed to vector particles for 4 hours followed by washing with phosphate buffer (PBS). Transduced cells were then further expanded for two days before lacZ-positive cells were detected by X-Gal staining. The uncertainty of the cfu per $\mathrm{ml}$ was $+/-9.5 \%$ of the measured value.

\section{Fixed Bed Reactor}

The fixed bed reactor consisted a two chamber system.

An axial flow vacuum insulated fixed bed with a working volume of $200 \mathrm{ml}$ was packed with FibraCell ${ }^{\circledR}$ cell culture carriers (New Brunswick Scientific, USA) and connected to the conditioning vessel (B.Braun International, Germany) in order to perfuse the immobilized cells. The volume of the conditioning vessel was kept between 500 and $2000 \mathrm{ml}$. The dissolved oxygen was measured in the conditioning vessel and concentration was held at 90 to $100 \%$ of air saturation level. The $\mathrm{pH}$ value of the medium was controlled at 7.1 by adjusting the $\mathrm{CO}_{2}$-concentration in the gas mixture. The medium in the conditioning vessel was changed batch wise. The fixed bed was inoculated with a suspension of exponentially growing cells by pumping them from the conditioning vessel into the fixed bed. The inoculum contained between $3 \times 10^{7}$ and $7 \times 10^{7}$ cells. 


\section{Filtration}

Cylindircal ceramic membrane with an outer diameter of $25 \mathrm{~mm}$ and 19 inner tubes with a diameter of $3 \mathrm{~mm}$ (Atech, Gladbeck, Germany) were used for cross flow filtration. As shown in figure 1 the membrane consists of a $\mathrm{Al}_{2} \mathrm{O}_{3}$ support material and two asymmetric layers. The first layer is built of zirconium oxide while the second layer that gives the cut off molecular size consists of $\mathrm{TiO}_{2}$. The membrane cutoff was specified with $20 \mathrm{kDa}$ by the manufacturer.

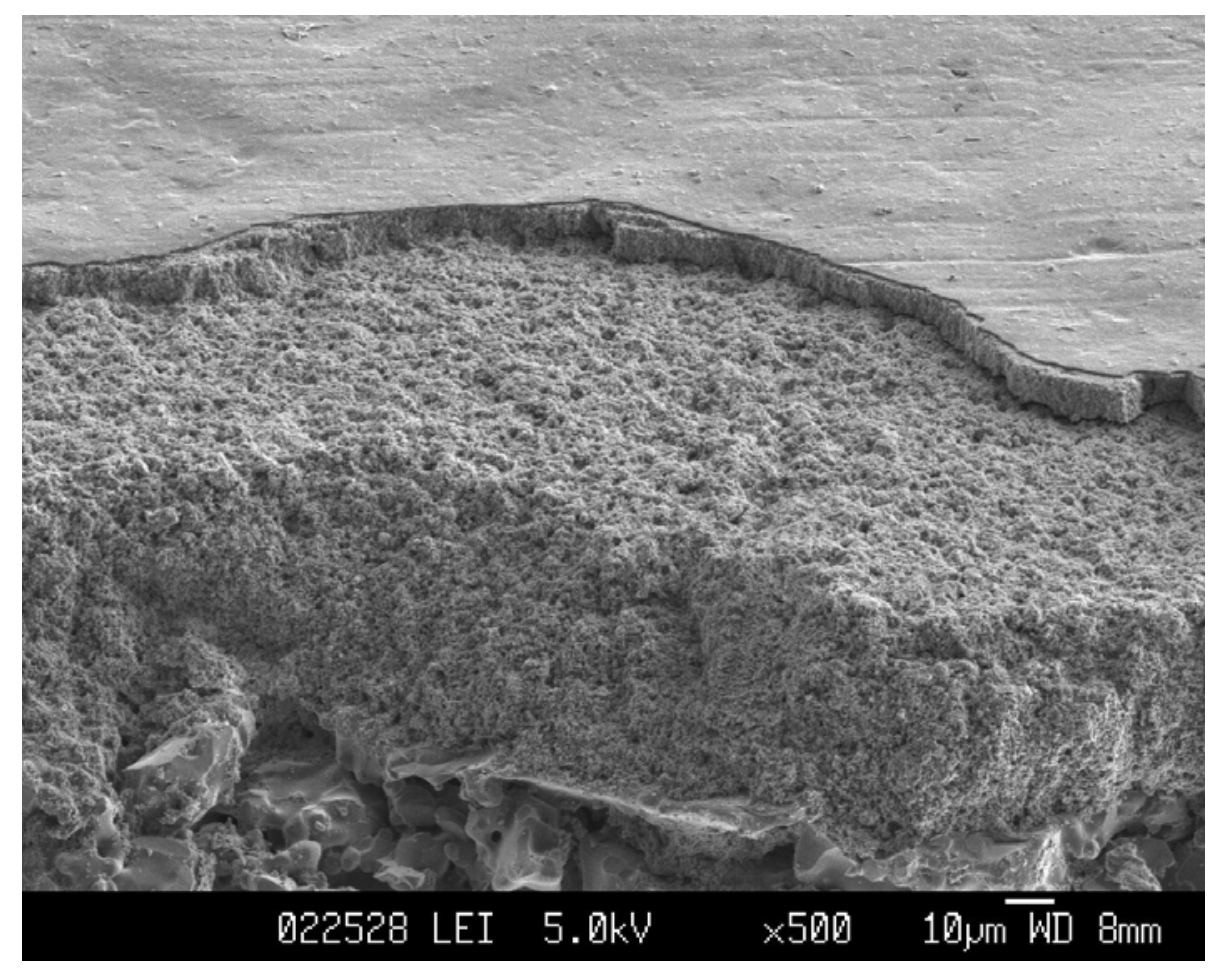

Figure 1. Cross section of a ceramic membrane showing three different layers. The one at the bottom is the support layer, in the middle is a layer with a smaller core diameter and on the top the functional membrane surface that is responsible for the membrane separation properties.

On the concentrate side of the membrane module a 11 glass bottle was connected to the inner side of the membrane. A peristaltic pump (Watlow, USA) with a flow rate of $2 \mathrm{~L} \mathrm{~min}^{-1}$ was used to circulate the vector containing supernatant. On the vacuum side of the device a 11 glass bottle was also installed and connected to the outer side of the filtration module. Furthermore a vacuum of 200 to 1000 mbar absolute pressure was applied to the filtration chamber while experiments with vector free media were carried out. The batch filtration experiments to concentrate vector particles were carried out at 400mbar transmembrane pressure. All chambers and tubes were cooled with crushed ice. By opening the valve of the vacuum tube the filtration was started and all weights were measured with a scale (Sartorius, Germay) 


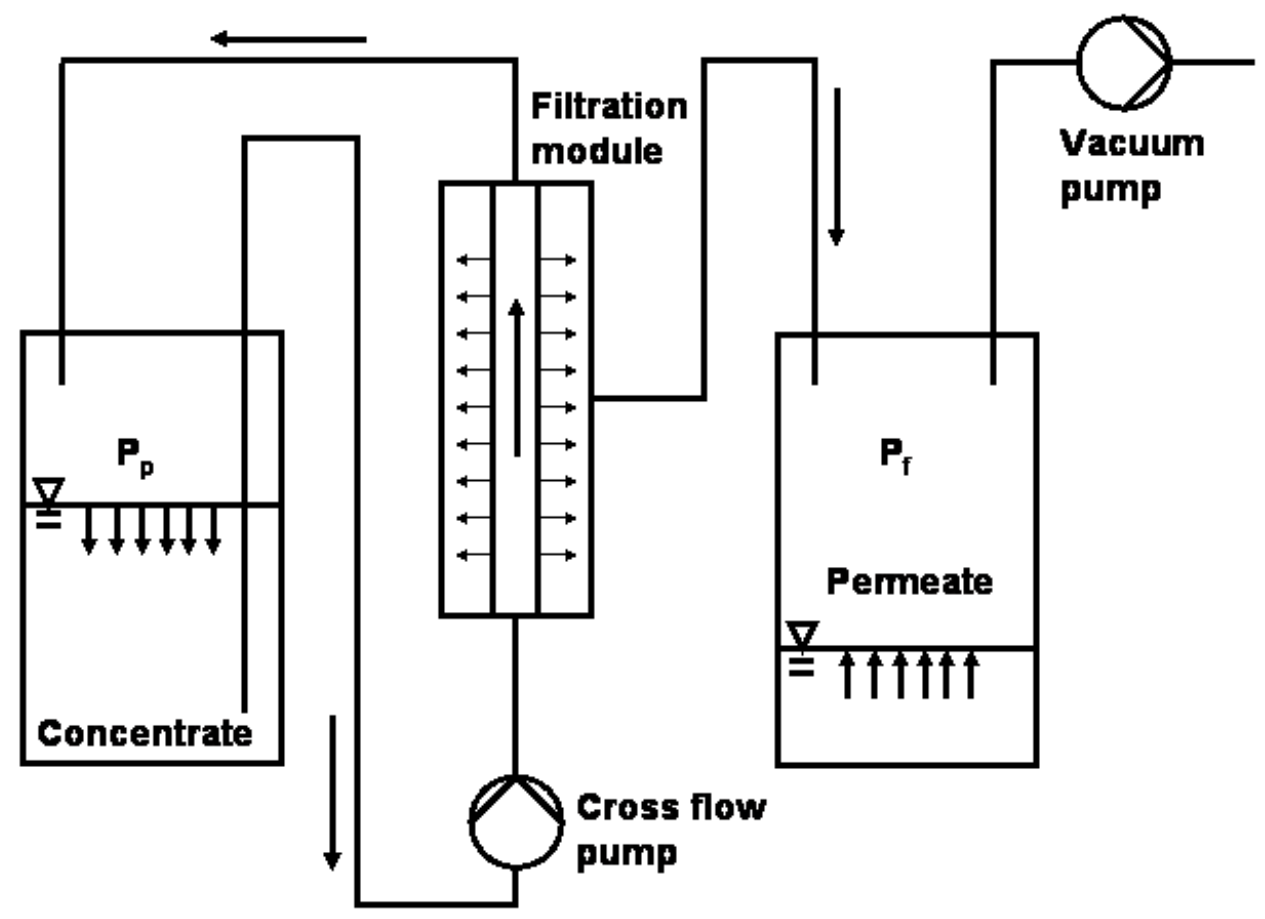

Figure 2. Experimental set up. The feed is pumped through the inner tubes of the ceramic membrane module. The driving force of the transmembrane flow was provided by the vaccum applied in the permeate vessel. Differential pressure was calculated by subtracting the absolute pressure values of permeate and concentrate vessels $P_{p^{-}} P_{f}=\Delta P$ and was kept constant during the entire process. (While performing a batch filtration the concentrate volume decreased and the permeate volume increased constantly until the process was stopped. This is obvious. Do you need to say this?)

\section{Software tools}

For model design and construction the software Stella ${ }^{\circledR} 7.0 .3$ (HPS Inc., USA) was used. This software was chosen because its graphical structure provides a good guide to develop a model from scratch, without the need for a previous deep mathematical analysis [16]. After receiving the mathematical expressions the equations were uploaded into Berkeley Madonna 8.0.1 in order to analyze the differential equations set. Berkeley Madonna is a program that numerically solves sets of ordinary differential equations (ODEs) and difference equations [12]. For analyzing and optimizing parameters of this work the multiple running function was used. The curve fit function was applied to optimize kinetic parameters of the model. With the statistical evaluation tool the fittings were subjected to a careful statistical analysis. 


\section{Basis of model}

Recombinant retroviruses or retroviral vectors can be 80 to $100 \mathrm{~nm}$ in diameter [1], so that that the physics of size exclusion and microfiltration can be applied [5] [17].

\section{General Model Filtration Process}

For conventional microfiltration the influence of different transmembrane pressure on the initial flow rate is given by Darcy's law.

$Q=\frac{\Delta P \cdot A}{\mu \cdot R_{M}}$

In 1982 Hermia [7] presented filtration laws for complete blocking, intermediate blocking, standard blocking and cake filtration. Physically derived models were applied to power law fluids. All four mechanisms were described by rate equations of permeate flow for constant transmembrane pressure. For blocking filtration the following equation was obtained:

$Q=Q_{0}-K_{b} \cdot V_{P}$

where $k_{b}$ the complete blocking constant and $Q_{0}$ the initial flow rate are described by:

$K_{b}=\frac{\Delta P \cdot \sigma}{\mu \cdot R_{M}}=K_{b 1} \cdot \Delta P \quad$ and $\quad Q_{0}=\frac{\Delta P \cdot A_{0}}{\mu \cdot R_{M_{0}}}=k \cdot \Delta P$

After substitution we obtain

$Q=k \cdot \Delta P-K_{b 1} \cdot \Delta P \cdot V_{P}$

which can be fitted to experimental data of different pressure set ups now. The constants of Hermia s four other filtration laws were substituted equally:

$Q=\frac{Q_{0}}{1+\frac{\sigma \cdot \Delta P}{\mu \cdot R_{M}} \cdot t} \Rightarrow Q=\frac{k \cdot \Delta P}{1+K_{i b} \cdot \Delta P \cdot t} \quad$ for intermediate blocking

$Q=\frac{Q_{0}}{\left(1+\frac{1}{2} \cdot K_{s b} \cdot Q_{0} \cdot t\right)^{2}} \Rightarrow Q=\frac{k \cdot \Delta P}{\left(1+\frac{1}{2} K_{s b} \cdot k \cdot \Delta P \cdot t\right)^{2}} \quad$ for standard blocking (6)

and

$Q=\frac{Q_{0}}{\left(1+2 \cdot K_{c} \cdot Q_{0}{ }^{2} \cdot t\right)^{1 / 2}} \Rightarrow Q=\frac{k \cdot \Delta P}{\left(1+2 \cdot K_{c} \cdot k^{2} \cdot \Delta P^{2} \cdot t\right)^{1 / 2}}$ for cake filtration. 
Other models comprising of the resistance of the membrane as well as the resistance of a reversible built up in the stagnant boundary layer appears in literature [6] [15] [17]. In case of constant membrane surface and layer dependant resistance, the flow rate is given by:

$\frac{1}{A} \frac{d V_{P}}{d t}=v_{T M}(t)=\frac{\Delta P}{\mu\left(R_{M_{0}}+R_{M_{c}}\right)}$

Field et al. [6] described a theory for cake filtration to predict transmembrane flow by including a cake erosion term in the basic overall resistance equation.

$$
R_{M}=R_{M_{0}}+R_{M_{c}}=R_{M_{0}}+\alpha \cdot\left(K_{c 2} \cdot \frac{V_{P}}{A}-\int_{0}^{t} S d t\right)
$$

Assuming $\mathrm{S}$ to be invariant with $t$, the transmembrane flow is described by

$$
Q=\frac{\Delta P \cdot A}{\mu \cdot\left(R_{M_{0}}+\alpha \cdot\left(K_{c 2} \cdot \frac{V_{P}}{A}-S \cdot t\right)\right.}
$$

which can be put in the following form if $A_{0}=A$ :

$$
Q=\frac{\Delta P}{\frac{1}{k}+\alpha \cdot \mu \cdot K_{c 2} \cdot \frac{V_{P}}{A^{2}}-\frac{\alpha \cdot \mu \cdot S \cdot t}{A}}=>Q=\frac{\Delta P}{\frac{1}{k}+K_{c 2^{*}} \cdot V_{P}-K_{c 3^{*}} \cdot t}
$$

While the model of Field et al. assumes that there is layer erosion occuringduring the entire filtration process, it can also be assumed that the layer resistance is proportional to the area specific layer mass $m$ and resistance $\alpha$ of the layer only. We then obtain:

$$
R_{M}=R_{M_{0}}+\alpha \cdot m
$$

To predict the permeate flow rate through the membrane it is necessary to define the equations for layer formation. Assuming that from the beginning of the filtration process all layer forming particles and substances of the feed flow is held back and incorporated into the boundary layer a mass balance was made. A fictitious layer forming substance LFS was introduced to describe the build up process of layer resistance. Based on the content of layer forming substance $c_{L F S_{R}}$ in the retentate, the mass $m$ of the boundary layer over the membrane is given by

$$
m_{\left[t<t_{1}\right]}=\frac{\int_{0}^{t} \rho_{L F S} \cdot Q_{L F S->m e m} d t}{A}=\frac{\int_{0}^{t} \rho_{L F S} \cdot Q \cdot \frac{c_{L F S_{R}}}{1-c_{L F S_{R}}} d t}{A}
$$

Layer formation can be described by two functions, assuming growth of the layer on the membrane surface continues until the maximum layer mass is reached and the mass balance 
of the layer forming substance (LFS) is in steady-state at a certain time $t_{1}$. In terms of Eq. 11 this means that there will be no decline of transmembrane flow.

This steady state of the layer mass can be explained by the critical flux theory of Field et al. which implicates while operation below a transmembrane flow of $Q_{\mathrm{c}}$ no further decline of filtrate flow will be observed [6]. An alternative explanation can be given by a force balance applied to layer forming substances or particles on the edge of the layer.

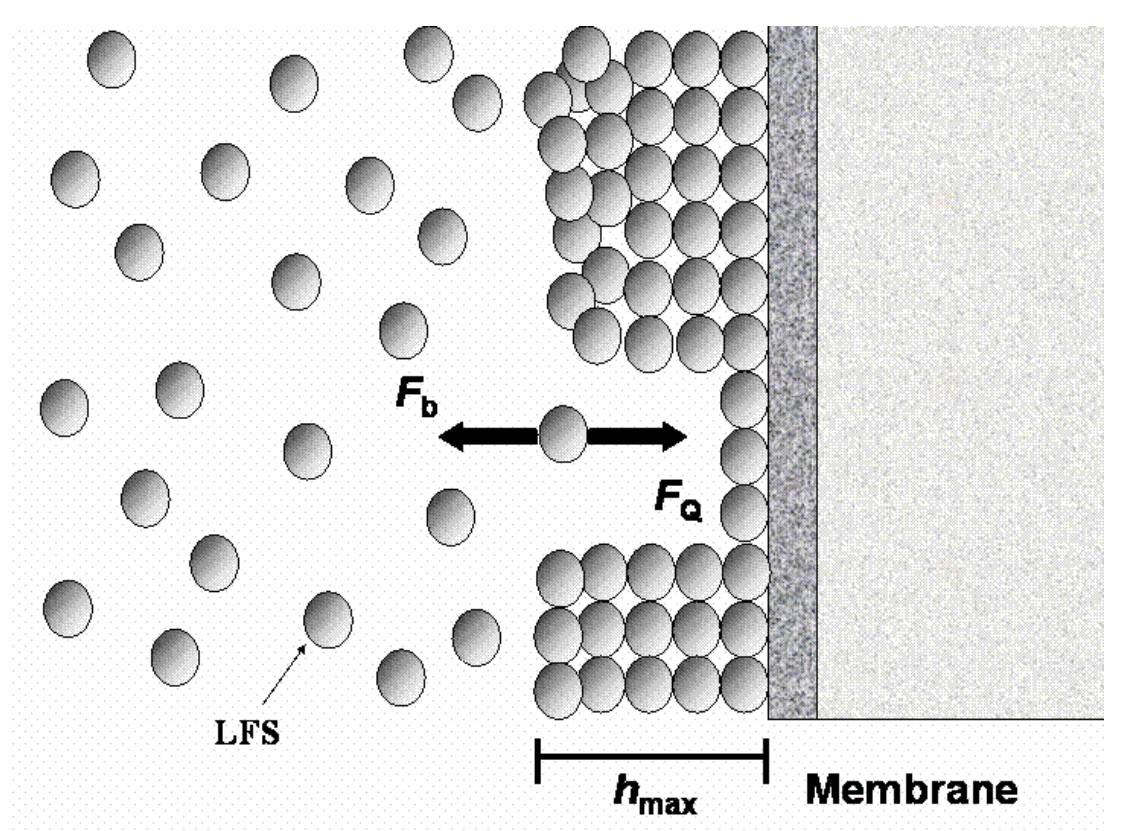

Figure 3. Force balance of the layer forming substance. To model the layer forming process it was assumed that the layer stops growing when the maximal height $h_{\max }$ is reached. The maximum height is marked by the steady-state of the force balance and is proportional to $m_{\max }$. The force on the layer forming substance $F_{\mathrm{Q}}$ induced by the transmembrane flow is considered to be equal at a height of $h_{\max }$ to the cross flow induced back force $F_{\mathrm{b}}$.

If the force of back diffusion $F_{\mathrm{b}}$, induced by concentration polarization and cross flow forces, exceeds the incorporation force of the transmembrane flow $F_{\mathrm{Q}}$, no further layer build up will take place. The mass of the layer is limited to a maximum area specific weight of mass $m_{\max }$ which is expressed by

$m_{\left[t>t_{1}\right]}=\frac{\int_{0}^{t_{1}} \rho_{L F S} \cdot Q \cdot \frac{c_{L F S_{R}}}{1-c_{L F S_{R}}} d t}{A}=m_{\max }$

Combing this relationship with Darcy's law, we obtain

$Q=\frac{\Delta P \cdot A}{\mu \cdot\left(R_{M_{0}}+\alpha \cdot m\right)} \Rightarrow>\frac{1}{v_{T M}(t)}=\frac{A}{Q}=\frac{\mu \cdot R_{M_{0}}}{\Delta P}+\frac{\mu \cdot \alpha \cdot m}{\Delta P}$

In constant pressure filtration $\Delta \mathrm{P}$ is constant. Furthermore we considered $\alpha$ and $\mu$ to be constant. Grouping the constant elements, Eq. 14 becomes: 
$\frac{1}{v_{T M}(t)}=\frac{K_{2}}{\Delta P}+\frac{K_{1}}{\Delta P} m$ or

At the beginning of filtration where $t=0$ and $\mathrm{m}=0$, it is easy to deduce from Eq. 15 that

$\frac{K_{2}}{\Delta P}=\frac{1}{v_{T M}(0)}=\frac{A}{Q_{0}}$

Finally the following is obtained:

$\frac{1}{v_{T M}(t)}=\frac{A}{Q_{0}}+\frac{K_{1}}{\Delta P} m$

The flow starts with $Q_{0}$ and is gradually decreased by the growing layer until a final constant permeate flow is achieved because the final constant layer mass is reached. This equation can be applied to microfiltration. It describes the transmembrane flow depending on the mass of the stagnant boundary layer and could be fitted to the experimental filtration data. Using fresh medium without layer forming ingredients, $Q_{0}$ can be easily determined.

In this work we studied the microfiltration of a fixed bed bioreactor medium containing fetal calf serum (FCS) and retroviral pseudo type vectors with a ceramic membrane. We assumed that the formation of the layer is principally related to a layer forming substance (LFS) which could have a FCS or protein content. Where there was no LFS we considered no layer formation and consequently no flow reduction by time. By increasing the LFS content in the medium layer formation begins and leads to reduction of transmembrane flow. Standard membrane filtration models to calculate transmebrane flow were fitted to experimental data and compared to the model. It was assumed that the mass of the layer stabilizes to a certain steady-state. Critical flux and fouling were not investigated in this study.

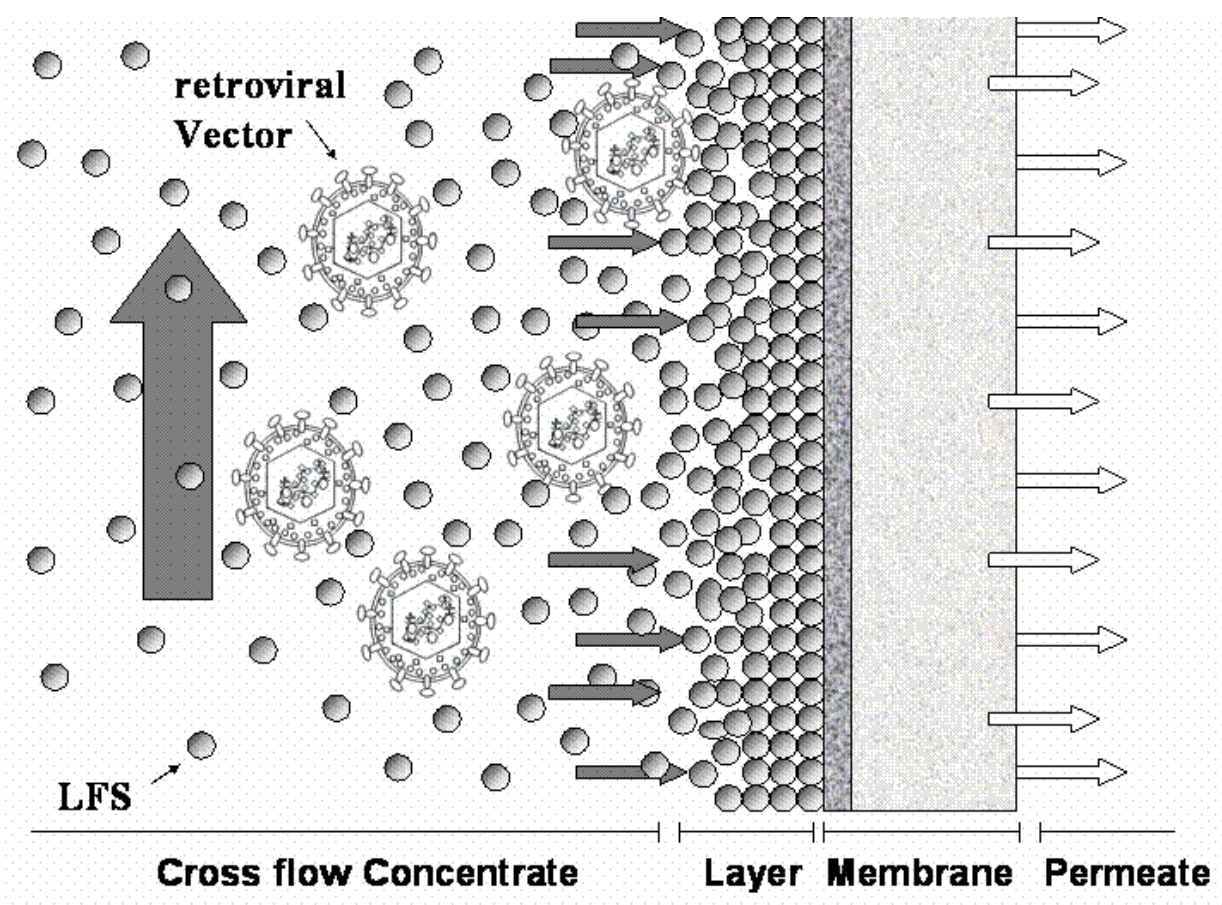


Figure 4. Schematic cross section of a membrane showing stagnant boundary layer formation and retroviral vector retention on the retentate side of the membrane. The transmembrane flow leads to a concentration of retentate contents that cannot pass the membrane. This process is described by layer formation. The more the boundary layer grows the more the LFS on the edge of the layer is exposed to sheer forces from the cross flow. The maximum layer mass is limited by the force balance on the edge of the layer or to cake layer erosion.

The steady-state mass of the layer is a function of viscosity, cross flow amount, transmembrane flow and LFS concentration in the retentate.

Layer formation can be described by Eq. 12 and Eq. 13, assuming growth of the layer on the membrane surface continues until the maximum layer thickness is reached and the mass balance of the LFS-layer is in steady-state. As described in Eq. 18 the flow of LFS at $t>t_{1}$ to and from the membrane surface is equal.

$Q_{L F S->m e m}=Q_{L F S<-m e m}$ 


\section{Batch filtration model including retroviral vectors}

For modeling a complete batch-filtration process all related volumes of retentate, permeate and membrane as well as the concentration of LFS and products have to be considered. Due to the lack of data concerning the concentrations of LFS at the membrane the transmembrane flow cannot be calculated directly. Instead a model structure will be introduced for fitting the calculations of the boundary layer formation to experimental data. For all model calculations according to Eq. 4, 5, 6, 7, 10 and 14 the following assumptions were made:

- Homogenous mixed vessels (model)

- Constant temperature at $4^{\circ} \mathrm{C}$ (experiment)

- Constant media viscosities (model)

- Constant pressure and cross flow

- Vector inactivation is driven by temperature decay (model)

For volume balances according to all standard models described by Eq. 4, 5, 6,7 and 10 a set of differential equations was set up.

$$
\frac{d V_{R}}{d t}=-Q
$$

to describe retenate volume reduction and

$$
\frac{d V_{P}}{d t}=Q
$$

to describe filtrate volume increase.

To implement the virus filtration and its decay a set of differential equations was added. In the case of $R=1$ we obtain

$$
\frac{d n_{A V_{R}}}{d t}=\frac{d V_{R} C_{A V_{R}}}{d t}=-C_{A V_{R}} \cdot Q \cdot(1-R)-C_{A V_{R}} \cdot k_{i}=-C_{A V_{R}} \cdot k_{i}
$$

for replication competent (active) retroviral vectors in the retentate and with $C_{A V_{P}(0)}=0$ active vector of the filtrate yields.

$$
\frac{d n_{A V_{P}}}{d t}=\frac{d V_{P} C_{A V_{P}}}{d t}=C_{A V_{R}} \cdot Q \cdot(1-R)-C_{A V_{P}} \cdot k_{i}=0
$$

Furthermore we receive the total amount of inactive vectors in permeate and retentate.

$$
\frac{d n_{I V R+P}}{d t}=C_{A V_{R}} \cdot k_{i}+C_{A V_{P}} \cdot k_{i}=C_{A V_{R}} \cdot k_{i}
$$

In comparison to the standard approaches additional assumptions were made for the model of reversible stagnant boundary layer formation as shown in Eq. 12,13 and 14. 
- Layer consists $100 \%$ of layer forming substance

- Until the maximum layer mass is reached all LFS flows to the membranes are incorporated into the boundary layer

- When maximum layer thickness is reached the flow of LFS to and from the membrane is equal

- The initial LFS content of the retentate is proportional to FCS concentration in the feed

The formation of layer and the volume change in batch cross flow filtration could be described by the filter equation Eq. 17, the step functions Eq. 12 and Eq. 13 describe layer formation and LFS-flow-steady-state when maximum layer mass is reached.

After introduction of LFS flow from $Q_{\mathrm{LFS}<-\mathrm{mem}}$ to the membrane layer $Q_{\mathrm{LFS}->\mathrm{mem}}$ we can derive a volume balance on the retentate.

$\frac{d V_{R}}{d t}=Q_{L F S<-m e m}-Q_{L F S->m e m}-Q$

Thus, the amount of LFS in the retentate $m_{R}$ in a Newtonian fluid will be given by

$\frac{1}{\rho_{L F S}} \cdot \frac{d m_{R}}{d t}=\frac{d V_{L F S_{R}}}{d t}=\left(Q_{L F S<-m e m}-Q_{L F S->m e m}\right)$

and the mass balance of the layer itself can be written:

$\frac{1}{\rho_{L F S}} \cdot \frac{d\left(m_{L F S}\right)}{d t}=\left(Q_{L F S->m e m}-Q_{L F S<-m e m}\right)$

where $m_{L F S}$ can be written as $m_{L F S}=A \cdot m$. According to Eq. 12 and 13 is possible to derive

$Q_{L F S->m e m}=\frac{Q \cdot c_{L F S_{R}}}{1-c_{L F S_{R}}}$

and $Q_{L F S<-m e m}$ is given by $Q_{L F S<-m e m[t<t 1]}=0$

and after period of time $t_{1} Q_{L F S<-m e m}$ yields to $Q_{L F S<-m e m[t>t 1]}=Q_{L F S->m e m}$

If we assume that all layer forming substances are included in the initial amount of the fetal calf serum of the feed we can achieve $c_{L F S_{R}}=k_{L F S} \cdot c_{F C S_{R}}$ and if $1-c_{L F S_{R}} \cong 1$ equation Eq. 14 can be put with $A_{0}=A$ in the following form:

$$
Q\left(t<t_{1}\right)=\frac{1}{\frac{1}{k \cdot \Delta P}+\frac{K_{1}^{*}}{\Delta P \cdot A^{2}} \cdot \int_{0}^{t} Q \cdot c_{F C S_{R}} d t}
$$


where $K_{1}^{*}$ is given by $K_{1}^{*}=\mu \cdot \alpha \cdot k_{L F S} \cdot \rho_{L F S}$. Hence, a constant area specific flow is reached at $t_{1}$.

$$
Q\left(t>t_{1}\right)=\frac{1}{\frac{1}{k \cdot \Delta P}+\frac{K_{1}^{*}}{\Delta P \cdot A^{2}} \cdot \int_{0}^{t 1} Q \cdot c_{F C S_{R}} d t}
$$

\section{Model architecture}

According to the differential equations Eq. 19 to 26 the model was constructed using two parts of the simulation software, Stella ${ }^{\circledR 7.0 .3 ~(H P S ~ I n c ., ~ U S A) ~ a n d ~ v o l u m e ~ a n d ~ v e c t o r ~ b a s e d ~}$ dependencies to parameters were arranged.

After construction of the model was finished, the system of algebraic and differential equations was transferred to Berkeley Madonna 8.0.1 in order to validate the model with the aid of experimental data. Inital input ranges or values of a model simultions are shown in table I.

\begin{tabular}{|c|c|c|c|c|c|}
\hline \multicolumn{6}{|c|}{ Table I. Range of inputs of model simulations } \\
\hline $\begin{array}{c}A \\
{\left[\mathrm{~cm}^{2}\right]}\end{array}$ & $\begin{array}{c}V_{R(\mathrm{t}=0)} \\
{\left[\mathrm{cm}^{3}\right]}\end{array}$ & $\begin{array}{c}c_{A V_{R}} \\
{\left[\mathrm{i} . \mathrm{u} \cdot \mathrm{ml}^{-1}\right]}\end{array}$ & $\begin{array}{c}k_{i} \\
{\left[\mathrm{~h}^{-1}\right]}\end{array}$ & $\begin{array}{c}\Delta P \\
{[\mathrm{bar}]}\end{array}$ & $\begin{array}{c}c_{F C S_{R}} \\
{\left[\mathrm{ml} \mathrm{ml}^{-1}\right]}\end{array}$ \\
\hline 1000 & $745-1794$ & $1.1 \times 10^{3}-3.2 \times 10^{5}$ & 0.0499 & $0.2-1.0$ & $0-0.05$ \\
\hline
\end{tabular}

By curve fitting to the experimental filtration data of permeate at different constant pressures, the above metioned models and their specific parameters were calculated. 


\section{Results}

The different flux models of microfiltration were compared by conducting experiments from 0.2 to 1 bar with 0.2 bar steps of transmembrane pressure and no vector particles in the feed feed. The feed had a $5 \%$ volume concentration of FCS. The initial transmembrane flow $Q_{0}$ was calculated from the permeate volume sloop of a filtration experiment with DMEM without any FCS content at 0.4 bar transmembrane pressure. Thus Eq. 3 yields

$Q_{0}(0.4 \mathrm{bar})=2759 \frac{\mathrm{ml}}{\mathrm{h}}=\frac{\Delta P \cdot A_{0}}{\mu \cdot R}=k \cdot 4 \cdot 10^{4} \frac{\mathrm{N}}{\mathrm{m}^{2}} \quad$ and $\quad k=6.897 \cdot 10^{-2} \frac{\mathrm{m}^{2} \mathrm{ml}}{\mathrm{Nh}}$

The model parameter $k$ was applied to the models of complete blocking, intermediate blocking, standard blocking, cake filtration, erosion cake layer filtration and limited layer mass filtration. By curve fitting, the model specific parameters were calculated as can be seen in table II. Each model was fitted to the five different pressure data sets and the correlation to all five data sets was calculated.

\begin{tabular}{|c|c|c|c|}
\hline \multicolumn{4}{|c|}{$\begin{array}{l}\text { Table II. Calculated model specific parameters for each model with } \\
k=6.897 \times 10^{-2} \mathrm{~m}^{2} \mathrm{ml} \mathrm{N}^{-1} \mathrm{~h}^{-1}\end{array}$} \\
\hline Law & Equation & Filtration constants & Correlation \\
\hline $\begin{array}{l}\text { Complete blocking } \\
\text { Eq. } 4\end{array}$ & $Q=k \cdot \Delta P-K_{b 1} \cdot \Delta P \cdot V_{P}$ & $K_{b 1}=1.31 \cdot 10^{-4} \frac{m^{2}}{h N}$ & 0.83 \\
\hline $\begin{array}{l}\text { Intermediate } \\
\text { blocking } \\
\text { Eq. } 5\end{array}$ & $Q=\frac{k \cdot \Delta P}{1+K_{i b} \cdot \Delta P \cdot t}$ & $K_{i b}=3.0 \cdot 10^{-4} \frac{m^{2}}{h N}$ & 0.95 \\
\hline $\begin{array}{l}\text { Standard blocking } \\
\text { Eq. } 6\end{array}$ & $Q=\frac{k \cdot \Delta P}{\left(1+\frac{1}{2} K_{s b} \cdot k \cdot \Delta P \cdot t\right)^{2}}$ & $K_{s b}=1.96 \cdot 10^{-4} \frac{1}{\mathrm{ml}}$ & 0.92 \\
\hline $\begin{array}{l}\text { Cake filtration } \\
\text { Eq. } 7\end{array}$ & $Q=\frac{k \cdot \Delta P}{\left(1+2 \cdot K_{c} \cdot k^{2} \cdot \Delta P^{2} \cdot t\right)^{1 / 2}}$ & $K_{c}=2.65 \cdot 10^{-6} \frac{h}{m l^{2}}$ & 0.96 \\
\hline $\begin{array}{l}\text { Cake erosion } \\
\text { Eq. } 10\end{array}$ & $Q=\frac{\Delta P}{\frac{1}{k}+K_{c 2^{*}} \cdot V_{P}-K_{c 3^{*}} \cdot t}$ & $\begin{aligned} K_{c 2^{*}} & =0.238 \frac{h N}{m^{5} \cdot m l} \\
K_{c 3^{*}} & =88.38 \frac{N}{m^{2} m l}\end{aligned}$ & 0.96 \\
\hline $\begin{array}{l}\text { Layer mass limit } \\
\text { Eq.30-31 }\end{array}$ & $\begin{array}{l}Q\left(t<t_{1}\right)=\frac{1}{\frac{1}{k \cdot \Delta P}+\frac{K_{1}^{*}}{\Delta P \cdot A^{2}} \cdot \int_{0}^{t} Q \cdot c_{F C S_{R}} d t} \\
Q\left(t>t_{1}\right)=\frac{1}{\frac{1}{k \cdot \Delta P}+\frac{K_{1}^{*}}{\Delta P \cdot A^{2}} \cdot \int_{0}^{t 1} Q \cdot c_{F C S_{R}} d t}\end{array}$ & $\begin{array}{l}K_{1}^{*}=127.08 \frac{10^{6} \mathrm{~kg}}{\mathrm{scm}} \\
\int_{0}^{t 1} Q \cdot c_{F C S_{R}} d t=12.19 \mathrm{ml}\end{array}$ & 0.98 \\
\hline
\end{tabular}

Cake filtration models showed a better correlation than the membrane blocking models as can be seen in table I and in figure 5. With a correlation of 0.98 the limited layer mass 
model correlates with more accuracy than the cake filtration model introduces by Hermia (correlation of 0.93) and the cake erosion model of Field et al. (correlation of 0.96). Thus, the physics of cake filtration or layer forming seem to describe the experimental data more suitable. Calculated filtrate volume was plotted against data for each model as shown in figure 5 to get an impression of the accuracy.
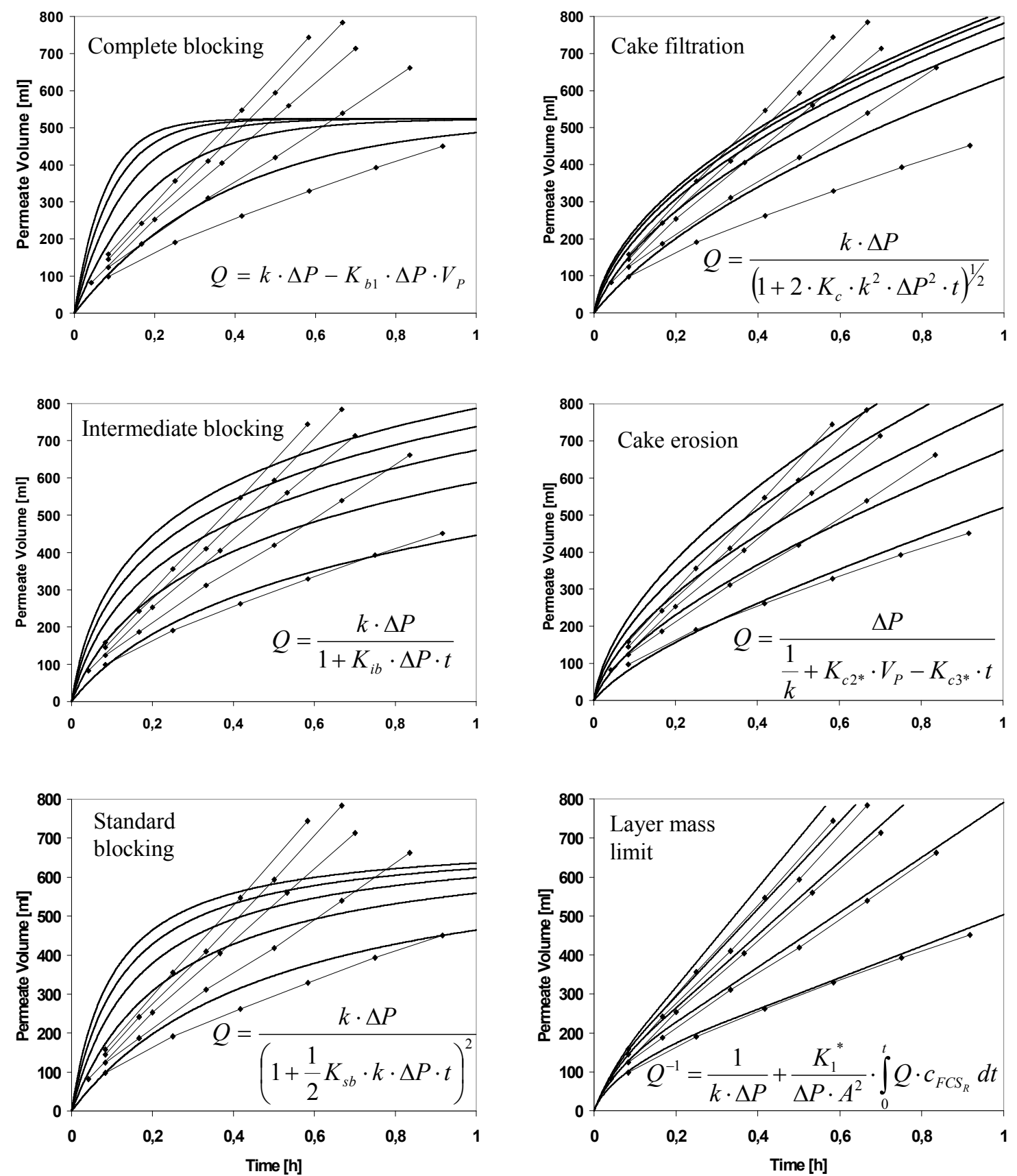

Figure 5: Fitting of all models ( - ) to experimental data $(\checkmark)$ of permeate increase. The batch filtrations were carried out at 0.2, 0.4, 0.6, 0.8 and 1 bar transmembrane pressure.

Furthermore curve fitting including $k$ was carried out. As can be observed in table III, the cake or layer related models indicate a significantly better accuracy in comparison to blocking models. However, the initial membrane resistances $k$ did not reach the experimental value of $6.89710^{-2} \mathrm{~m}^{2} \mathrm{ml} \mathrm{N}^{-1} \mathrm{~h}^{-1}$ in any of these models with accuracy. 


\begin{tabular}{|l|c|l|c|}
\hline \multicolumn{3}{|l|}{ Table III. Calculated model parameters and $k$ for each model } \\
\hline Law & $\begin{array}{l}k \\
{\left[\mathrm{~m}^{2} \mathrm{ml} \mathrm{N}^{-1} \mathrm{~h}^{-1}\right]}\end{array}$ & Filtration constants & Correlation \\
\hline $\begin{array}{l}\text { Complete blocking } \\
\text { Eq. 4 }\end{array}$ & 0.0266 & $K_{b 1}=2.88 \cdot 10^{-5} \frac{\mathrm{m}^{2}}{\mathrm{hN}}$ & 0.96 \\
\hline $\begin{array}{l}\text { Intermediate } \\
\text { blocking } \\
\text { Eq. 5 }\end{array}$ & 0.0313 & $K_{i b}=6.1 \cdot 10^{-5} \frac{\mathrm{m}^{2}}{\mathrm{hN}}$ & 0.96 \\
\hline $\begin{array}{l}\text { Standard blocking } \\
\text { Eq. 6 }\end{array}$ & 0.032 & $K_{s b}=4.79 \cdot 10^{-5} \frac{1}{\mathrm{ml}}$ & 0.96 \\
\hline $\begin{array}{l}\text { Cake filtration } \\
\text { Eq. 7 }\end{array}$ & 0.0294 & $K_{c}=1.33 \cdot 10^{-6} \frac{\mathrm{h}}{\mathrm{ml}}$ & 0.99 \\
\hline $\begin{array}{l}\text { Cake erosion } \\
\text { Eq. 10 }\end{array}$ & 0.0279 & $K_{c 2^{*}}=0.173 \frac{\mathrm{h} \mathrm{N}}{\mathrm{m}^{5} \cdot \mathrm{ml}}$ & 0.99 \\
\hline $\begin{array}{l}\text { Layer mass limit } \\
\text { Eq.30-31 }\end{array}$ & 0.1433 & $K_{c 3^{*}}=101.96 \frac{\mathrm{N}}{\mathrm{m}^{2} \mathrm{ml}}$ & \\
\hline
\end{tabular}

To investigate the hypothesis of a layer forming substance and its relation to the concentration of fetal calf serum $t$, an experiment with different FCS content was carried out.

Vector free medium batches containing $0,1,3$ and 5\% concentration of FCS, with volumes of $1000 \mathrm{ml}$, were filtrated using a $20 \mathrm{kDa}$ molecular weight cut-off membrane. Each experiment was repeated four times to monitor the transmembrane flow against time.

Cross flow filtration was stopped after $0.5 \mathrm{~h}$ or after final retentate volumes of $100 \pm 30 \mathrm{ml}$ were reached.

As can be observed in figure 6 the increase of permeate volume slows down with time. 


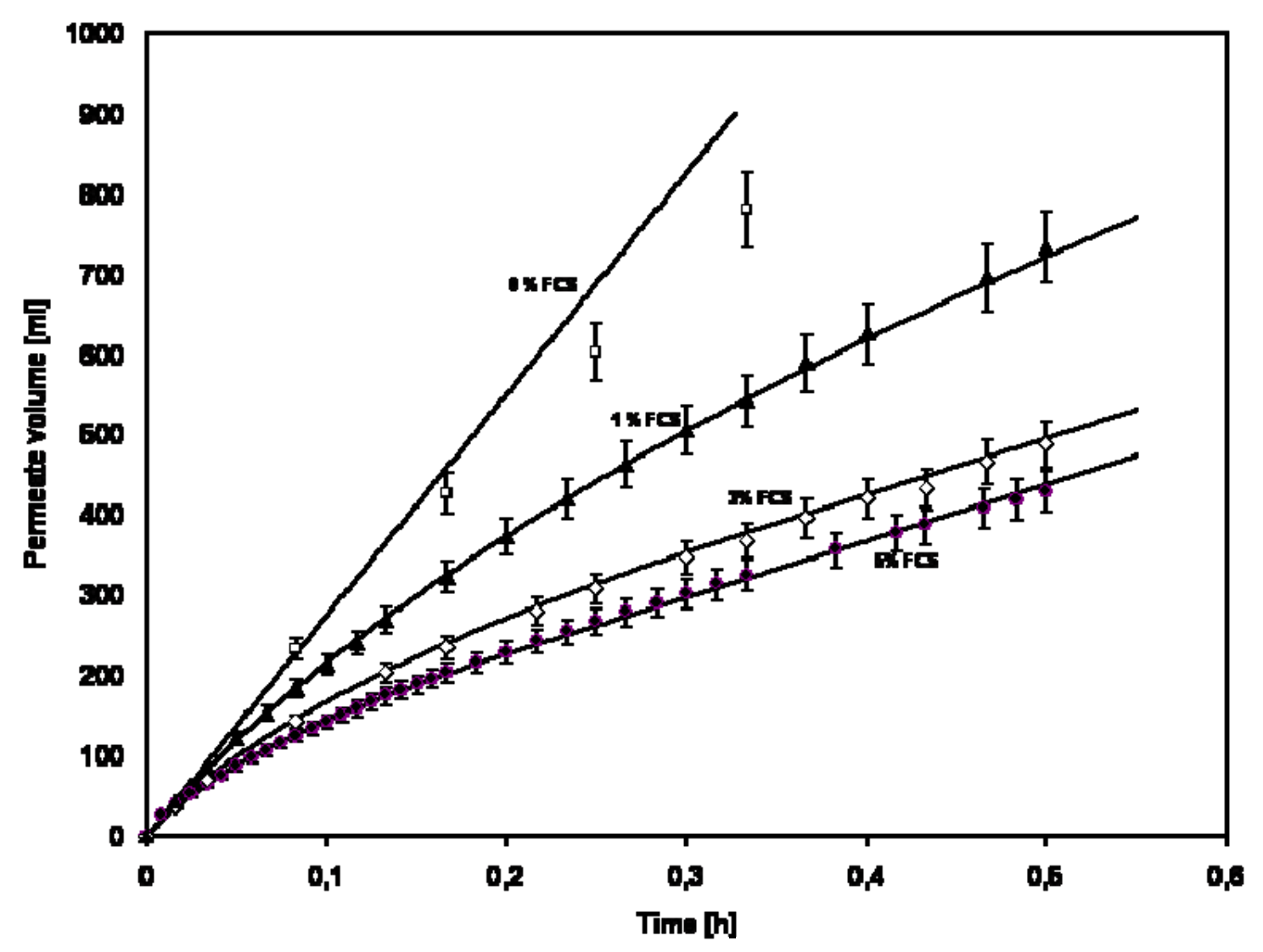

Figure 6. Time course of filtration volume of 11 vector free medium containing 0 ( $\square$ ), $1(\boldsymbol{\Delta}), 3(\diamond)$ and $5 \%$ FCS $(\bullet)$ at a transmembrane pressure of 0.4 bar using an $\mathrm{Al}_{2} \mathrm{O}_{3}$ ceramic membrane with a cut off of $20 \mathrm{kDa}$. The volume of permeate is increasing according to the transmembrane flow. Simulated curves were calculated by solving equations Eq. 30 and Eq.31 with the parameters of table II. The maximum total permeate volume was $1000 \mathrm{ml}$.

Transmembrane flow at the start of the filtration process appears to be the same for all the different mediaAs the FCS concentration is increased, the transmembrane flow decreases. Transmembrane flow without FCS in the medium was expected to be constant during the entire filtration process until the final volume of retentate was reached. However there is a slightly decrease in the flow which results in a discrepancy in permeate volume compared to the simulated volume. The simulated final permeate volume was reached after $0.31 \mathrm{~h}$ while the experimental final volume was reached after $0.5 \mathrm{~h}$. These results could be explained by the influence of components in fresh serum free medium. Larger molecules present in the medium are concentrated on the concentrate side of the membrane which leads also to a layer formation on the membrane surface.

Figure 6 shows that with increasing FCS concentration the transmembrane flow decreases. The higher the FCS concentration the earlier a constant permeate flow is reached. This indicates that the boundary layer is built up to its final maximum mass faster with higher FCS concentration.

Making the aforementioned simplifying assumptions the model was fitted to the experimental time courses of the permeate volume.

To determine the stagnant boundary layer formationand its effect on the transmembrane flow the model run with the parameters of table II and different initial FCS content. The maximum permeate flow at the beginning of the filtration process, to obtain the initial flow 
coefficient, was assumed to be $2.7591 \mathrm{~h}^{-1}$.As can be observed in figure 6 the model explains the variation of 1,3 and 5\% FCS content with accuracy according to permeate volume over time. It is clear that a higher concentration of FCS, which was considered to be the driving force of layer forming, caused higher resistance to flow, so that a smaller flow through the membrane was obtained. The experiment without FCS shows, as expected, the most rapid increase of the permeate volume. Assuming that there is no layer forming substance, the volume of permeate should increase constantly. However figure 6 indicates that, in this case, the transmembrane flux is lower than predicted by the model which seems to be an effect of layer forming of substances like proteins or sugar oligomeres, which are still in the medium or produced by the cells.

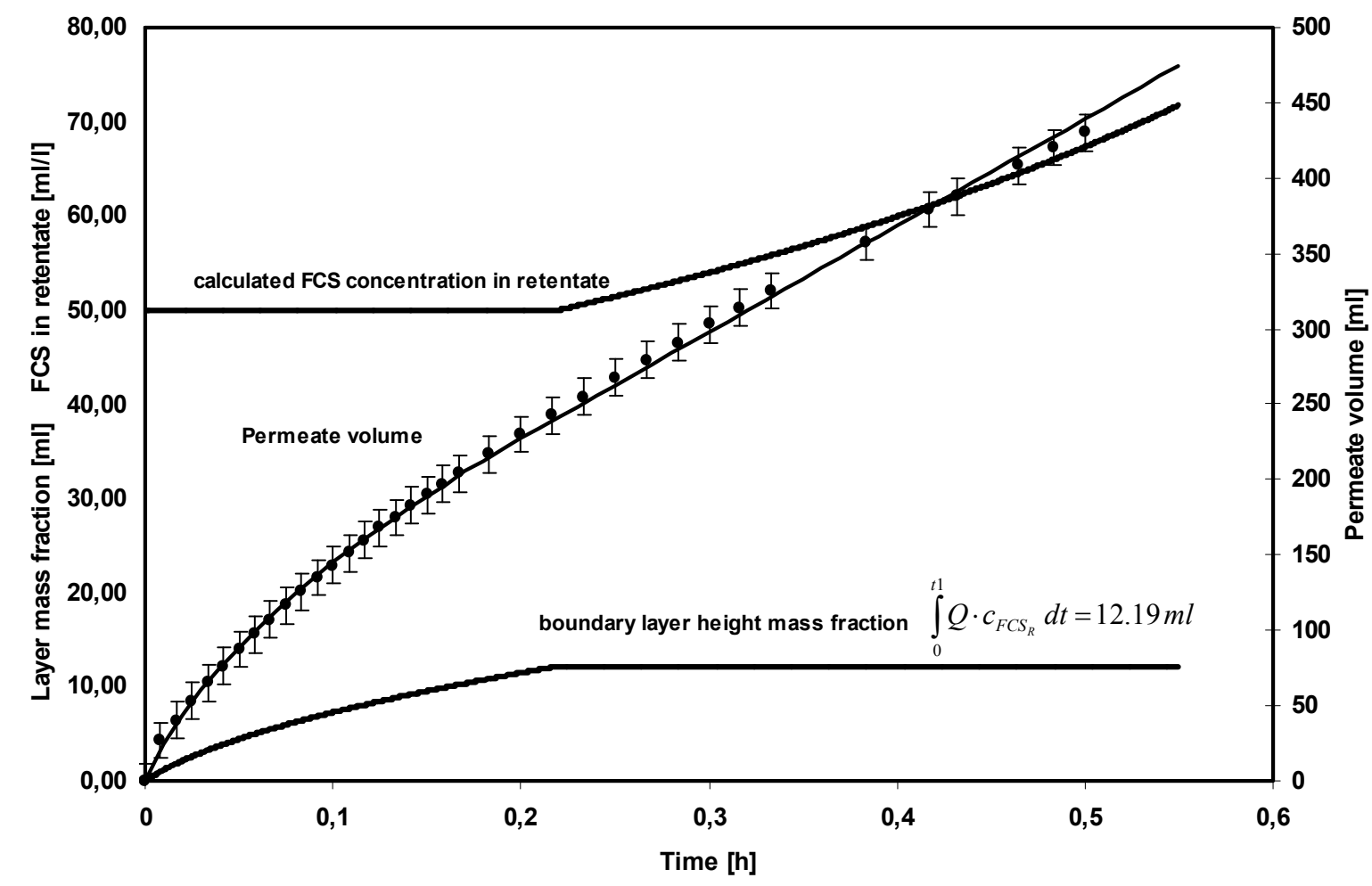

Figure 7. Calculated layer mass fraction and the related increase of FCS concentration in concentrate during a batch filtration of 11 DMEM containing 5\% FCS at 0.4 bar transmembrane pressure. Model parameters were taken from table II. The solid lines represent calculated layer mass, permeate volume and FCS concentration in retentate using the parameters presented.

From figure 6 it seems to be clear that the FCS concentration has a major influence on transmembrane flow. This mechanism was explained by the layer forming filtration model introduced above. As shown in figure 7 the layer increased until the maximum height mass was reached. By the start of the filtration process the model supposes, that all layer forming substance was transported by the transmembrane flow to the surface of the membrane to be completely incorporated into the layer. In fact due to the lack of back transportation one would expect that there is no increase in FCS concentration in the concentrate medium at the beginning. Once the layer mass is stabilized the concentration of the FCS starts to increase in the medium as can be seen in figure 7.

The results were confirmed for other experiments carried out with different transmembrane pressure of 0.2 and 1 bar and 0 and 5\% FCS concentration. 


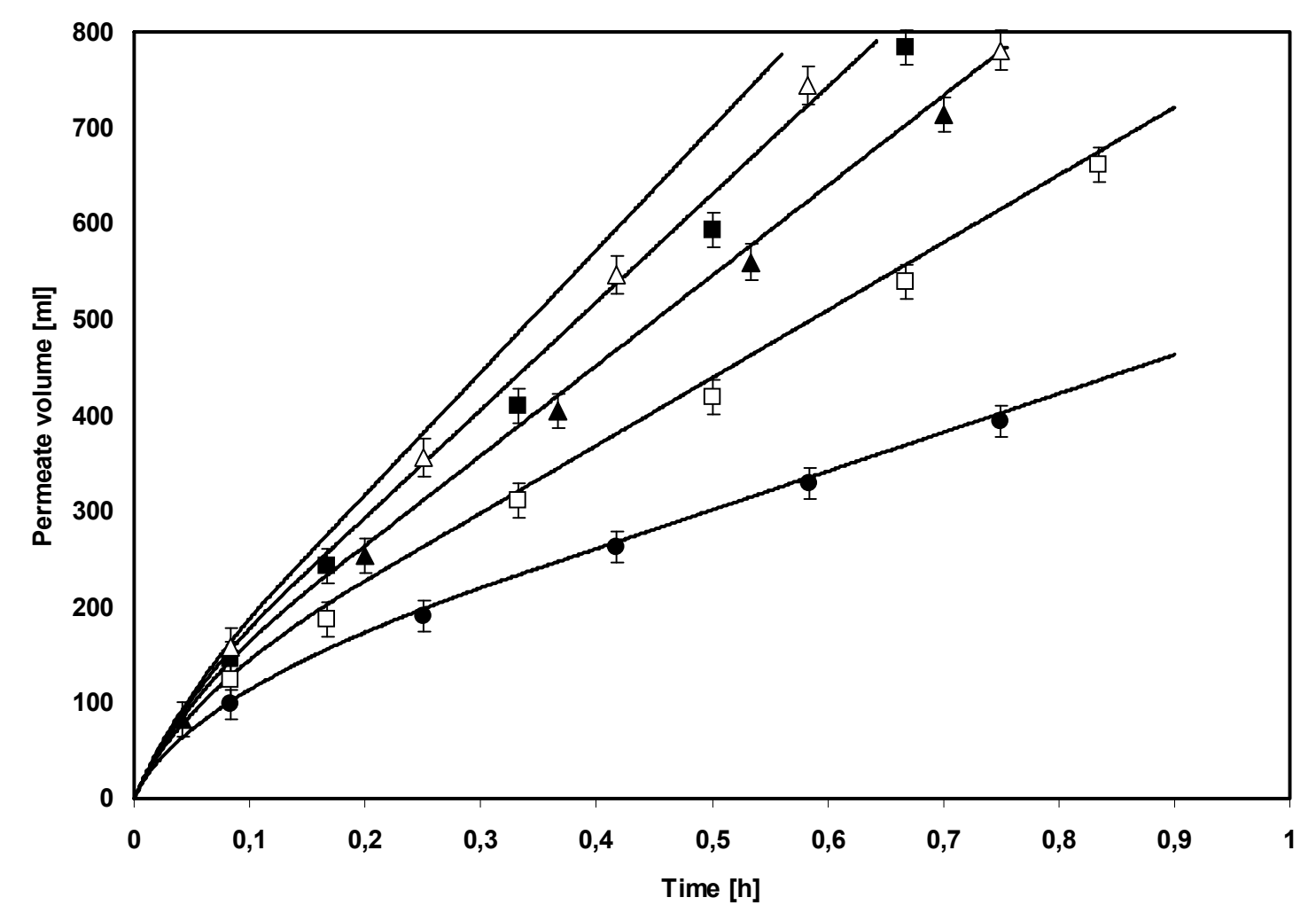

Figure 8. Time course of permeate volume of 5\% FCS containing DMEM at $0.2(\bullet), 0.4$ $(\square), 0.6(\mathbf{\Delta}), 0.8(\mathbf{\square})$ and 1 bar $(\Delta)$ differential tansmembrane pressure. To eliminate the effect of different process times under different conditions of pressure the concentration factor of transduction competent virus particles including the vector decay was plotted against permeate volume.

Figure 8 indicates that the maximum permeate flow is a function of pressure according to Darcy's law, while the decrease in transmembrane flow of 5\% FCS containing DMEM is well described by the model. However the model was designed to determine batch filtration operation at constant transmembrane pressure. Assuming that the pressure does not compress the boundary layer in the range of 0.2 to 1 bar it appears possible to use equation Eq. 3 to calculate the initial maximum flow rate through the membrane.

The effect of pressure on the transmembrane flow is rather strong. Applying the model to transmembrane pressure above 0.6 bar the measured data of permeate volumes were below the simulated ones. This indicates that, in this case, the transmembrane flow is less than the model predicts. This effect could be explained by layer compressions and a resulting increase in the membrane resistance. However as expected the flow velocity through the membrane could be enhanced by increasing the pressure.

Having established these model parameters describing the transmembrane flow the kinetics of vector degradation and retention were investigated.

The rate of virus decay at a filtration temperature $\left(4^{\circ} \mathrm{C}\right)$ was measured from the same supernatant that was taken for the other experiments. Considering logarithmic degradation of the active virus a decay rate at $4{ }^{\circ} \mathrm{C} \mathrm{k}_{\mathrm{i}}$ was $0,0499 \mathrm{~h}^{-1} \pm 0.0004$ with a correlation coffecient of 0.9913 . 
After batch filtration experiments (table IV), the permeate was analyzed for infective vector particles. No vector particles were measured in pure supernatant so that the retention factor of the membrane was set to $\mathrm{R}=1$.

Having determined the required parameters, the model was used to predict the infective virus concentration in the retentate of several permeated batches (table IV).

For this purpose the aforementioned set of differential equation was numerically solved using the previously determined parameters for each set of conditions related to the batches. A total of 16 batches of clarified vector containing supernatant taken out from a fix bed reactor cultivation were permeated using a $20 \mathrm{kDa}$ cut-off ceramic membrane. This membrane was selected since it should allow the complete retention of all vector particles $(<60 \mathrm{kDa})$ in the retentate. As can be observed in table II the volume of one batch was 1794 $\mathrm{ml}$ while the other 15 batches had volumes of between 745 and $947 \mathrm{ml}$. The lower 14 batches were taken in between the first 20 days of the cultivation and showed transduction competent viruses above $10^{5} \mathrm{cfu} / \mathrm{ml}$. The liquid volume reduction of all processed batches was between 5.2 and 13.7 fold while the increase of the vector titer was 4.3-10.1 fold. The average titer was $1.8 \pm 2.410^{5} \mathrm{cfu} / \mathrm{ml}$ and that in the concentrated product was

$1.4 \pm 2.110^{6} \mathrm{cfu} / \mathrm{ml}$. A mean recovery of transduction competent virus of $84.6 \pm 9.0 \%$ compared to the model calculated vector titer was achieved. 


\begin{tabular}{|c|c|c|c|c|c|c|c|c|c|c|c|}
\hline \multirow[b]{2}{*}{$\begin{array}{l}\text { Process } \\
\text { conc.factor* }\end{array}$} & \multicolumn{4}{|c|}{ Feed } & \multicolumn{5}{|c|}{ Retentate } & \multirow{2}{*}{\multicolumn{2}{|c|}{${ }_{*}$ Filt. Time }} \\
\hline & $\begin{array}{l}\text { Volume } \\
{[\mathrm{ml}]}\end{array}$ & $\begin{array}{l}\text { CFU } \\
\left(\times 10^{6}\right)\end{array}$ & $\begin{array}{c}\mathrm{CFU} / \mathrm{ml} \\
\left(\times 10^{4}\right)\end{array}$ & $\begin{array}{c}\text { Std dev. } \\
\left(\times 10^{3}\right)\end{array}$ & $\begin{array}{l}\text { Volume } \\
\text { [ml] }\end{array}$ & $\begin{array}{l}\text { CFU } \\
\left(\times 10^{6}\right)\end{array}$ & $\begin{array}{c}\mathrm{CFU} / \mathrm{ml} \\
\left(\times 10^{4}\right)\end{array}$ & $\begin{array}{c}\text { Std dev. } \\
\left(\times 10^{3}\right)\end{array}$ & $\begin{array}{c}\text { CFU/ml } \\
\left(\times 10^{4}\right) \\
\text { model }\end{array}$ & & \\
\hline 7.5 & 947 & 1.04 & 0.11 & 0.05 & 102 & 0.84 & 0.82 & 0.91 & 0.97 & $85.11 \%$ & 1.17 \\
\hline 5.4 & 852 & 3.80 & 0.45 & 0.33 & 136 & 3.25 & 2.39 & 2.45 & 2.67 & $89.46 \%$ & 1.17 \\
\hline 10.1 & 1794 & 372.82 & 20.78 & 20.30 & 131 & 274.48 & 209.53 & 146.23 & 254.00 & $82.49 \%$ & 2.50 \\
\hline 6.7 & 870 & 104.40 & 12.00 & 11.49 & 110 & 88.11 & 80.10 & 0.16 & 90.50 & $88.51 \%$ & 1.00 \\
\hline 5.9 & 930 & 193.44 & 20.80 & 18.59 & 123 & 151.29 & 123.00 & 85.30 & 149.00 & $82.55 \%$ & 1.00 \\
\hline 4.3 & 745 & 159.43 & 21.40 & 29.59 & 142 & 130.64 & 92.00 & 95.12 & 107.00 & $85.98 \%$ & 1.00 \\
\hline 8.4 & 812 & 262.28 & 32.30 & 65.88 & 75 & 203.25 & 271.00 & 149.11 & 333.00 & $81.38 \%$ & 1.00 \\
\hline 8.3 & 903 & 81.27 & 9.00 & 9.96 & 93 & 69.10 & 74.30 & 39.39 & 82.70 & $89.84 \%$ & 1.17 \\
\hline 9.4 & 895 & 167.37 & 18.70 & 16.50 & 74 & 129.50 & 175.00 & 40.65 & 214.00 & $81.78 \%$ & 1.17 \\
\hline 7.4 & 923 & 161.53 & 17.50 & 19.39 & 97 & 125.13 & 129.00 & 64.09 & 158.00 & $81.65 \%$ & 1.17 \\
\hline 7.3 & 906 & 77.01 & 8.50 & 8.47 & 101 & 62.72 & 62.10 & 68.40 & 72.20 & $86.01 \%$ & 1.17 \\
\hline 9.1 & 853 & 123.69 & 14.50 & 13.63 & 78 & 102.96 & 132.00 & 31.41 & 151.00 & $87.42 \%$ & 1.00 \\
\hline 7.9 & 845 & 184.21 & 21.80 & 11.35 & 82 & 141.86 & 173.00 & 75.74 & 214.00 & $80.84 \%$ & 1.00 \\
\hline 7.8 & 934 & 166.25 & 17.80 & 18.74 & 94 & 130.66 & 139.00 & 51.01 & 167.00 & $83.23 \%$ & 1.17 \\
\hline 7.6 & 784 & 157.58 & 20.10 & 29.46 & 83 & 126.16 & 152.00 & 122.68 & 180.00 & $84.44 \%$ & 1.00 \\
\hline 5.9 & 853 & 133.92 & 15.70 & 7.56 & 121 & 111.32 & 92.00 & 173.91 & 105.00 & $87.62 \%$ & 1.00 \\
\hline
\end{tabular}

* Process concentration factor: Theoretical increase factor of vector concentration in the retentate.

** Recovery: Amount of active vector particles in final retentate divided by the initial amount in the feed

As can be observed in figure 9 the model explains the variation of the transduction competent vector accurately in the first $60 \mathrm{~min}$ of filtration using a wide range of feed concentrations from $10^{3}$ to $10^{5} \mathrm{cfu} / \mathrm{ml}$. Although vector decay was implemented into the model the measured vector concentration at the end of the filtration reaches a $84.6 \pm 9.0 \%$ recovery of the predicted concentration only.

From this observation two conclusions can be drawn. First, the increase inserum concentration like proteins on the surface of the membrane and the increase inserum concentration at the end of the filtration causes more rapid vector inactivation. Second, there was no system related decay of vectors in the first $40 \mathrm{~min}$ of the filtration which confirms the model assumptions and simplifications. 


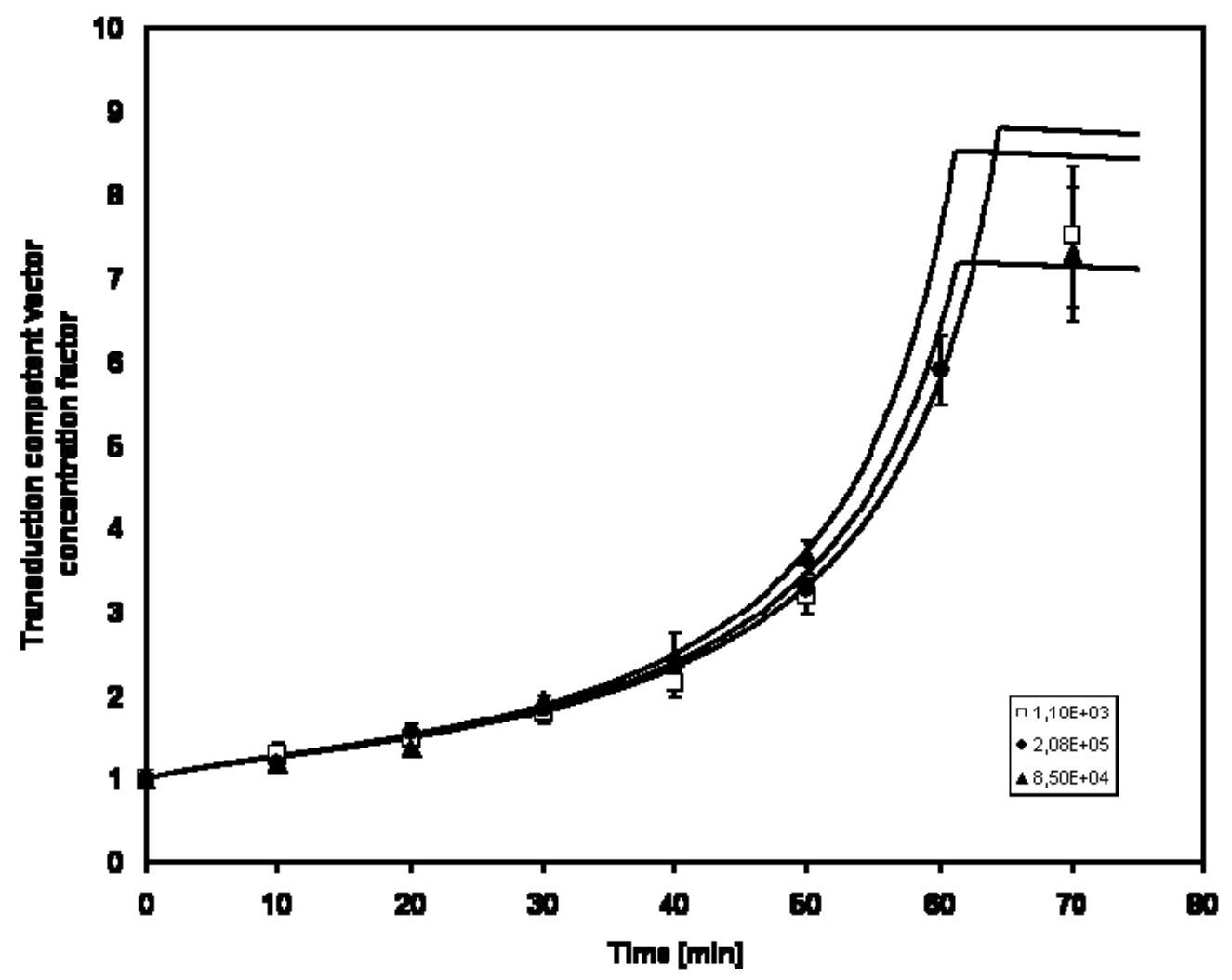

ure 9. Fitting of the model to the normalized vector titer concentration factor in the retentate, taking feeds of $1.1 \pm 0.3 \times 10^{3} \mathrm{cfu} / \mathrm{ml}(\square), 2.1 \pm 0.2 \times 10^{5} \mathrm{cfu} / \mathrm{ml}(\bullet)$, and $8.5 \pm 0.8 \times 10^{4} \mathrm{cfu} / \mathrm{ml}(\boldsymbol{\Delta})$ active vector for batch filtration. After the final permeate volume was reached the concentration did not increase anymore which is given by the maximum concentration after approximately $60 \mathrm{~min}$ filtration time.

Process Optimization

The developed model was applied to determine the operational parameters membrane area and batch volume in order to achieve the highest vector concentration. 


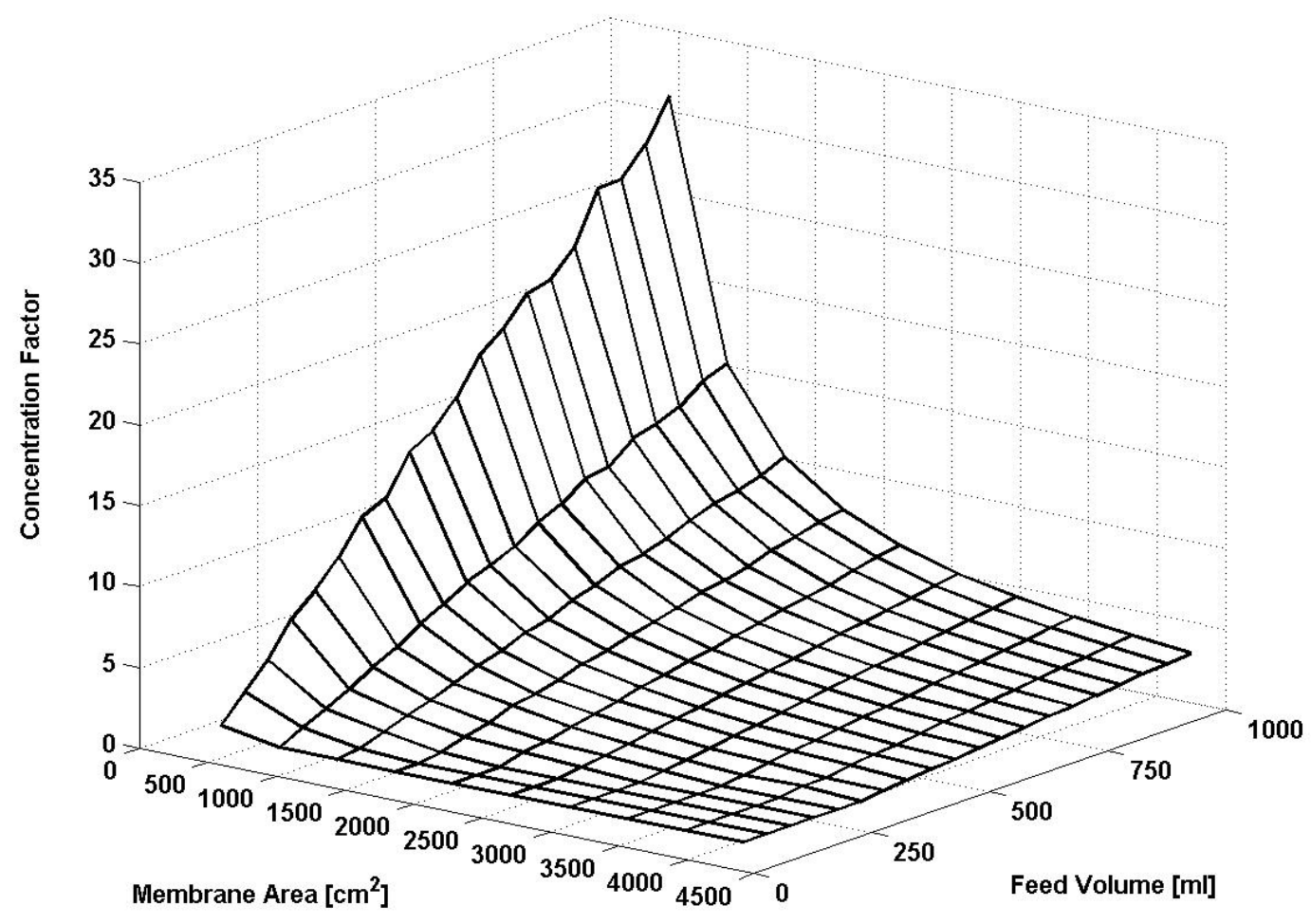

Figure 10. Results of model simulations by altering membrane area and feed volume. Theoretically a maximum concentration factor of approximately 30 fold could be reached in vector concentration. Calculations include vector decay and concentrate volume limitation which is proportional to the membrane area.

Results concerning the vector titer show in figure 10 that the maximal batch volume and minimal membrane area should lead to the highest vector concentration. Concentrations of up to 30 fold may be achievable depending on the layer forming when using smaller membrane surfaces. However these concentrations were not reached by experiments carried out here due to the fact that only $1000 \mathrm{~cm}^{2}$ membrane area was used. Nevertheless the simulation shows efficiency of the filtration process as long the transmembrane flow could be set within the predicted range so that the overall filtration time is equal to the model data.

\section{Conclusion}

The model described in this work could explain and predict the batch filtration process based on experimental data. This model was developed to calculate the transmembrane flow and the titer of infective vector particles in the concentrate. By introducing equations for layer formation on the concentrate side of the membrane a non- stationary filtration process is described. This result emphasizes the layer forming theory assumed in this work. However the model shows discrepancies with the experimental data at differential pressure above 0.6 bar and the vector concentration deviates by more than $15 \%$ when the retentate is concentrated by more than 6 to 7 fold. Thus further modeling approaches should take more than one layer forming substance into account. The influence of the vector particles themselves on inactivation and diffusion effects on the membrane surface should be considered. 
The model showed a significant benefit in increasing the transmembrane flow by either higher transmembrane pressure or a larger amount of membrane surface and the subsequent reduction of filtration time. It also revealed a clear advantage in using a low concentration of FCS or protein in the cell culture medium. By reducing the filtration time virus degradation is subsequently reduced.

By the aid of the model an optimization of the parameters' membrane surface A and feed volume observation of the transduction competent vector concentration CAV in the concentrate was achieved without the need for expensive filtration experiments.

In terms of future developments for production and downstream processing purposes, this model can be integrated into the model architecture of the production process of the bioreactor and other downstream processing steps like ultrafiltration. Furthermore equations to predict the storage behavior of the vector particles should be integrated. The model can also be used for different cell lines, alternative production systems and filtration processes. Further investigations concerning the filtration process and the effect of different set ups like dead end filtration or continuous processing should be carried out. Fianlly the effects of system dependant vector decay should be investigated.

\section{List of symbols}

\begin{tabular}{|c|c|c|}
\hline$A$ & {$\left[\mathrm{~m}^{2}\right]$} & Membrane area \\
\hline$A_{0}$ & {$\left[\mathrm{~m}^{2}\right]$} & Membrane area \\
\hline$c_{F C S_{R}}$ & {$\left[\mathrm{~m}^{3} \mathrm{~m}^{-3}\right]$} & Concentration of FCS in the retentate \\
\hline$c_{L F S_{R}}$ & {$\left[\mathrm{~m}^{3} \mathrm{~m}^{-3}\right]$} & Concentration of LFS in the retentate \\
\hline$C_{A V_{R}}$ & {$\left[\mathrm{cfu} \mathrm{ml}{ }^{-1}\right]$} & Concentration of infective vector particles in retentate \\
\hline$C_{A V_{P}}$ & {$\left[\mathrm{cfu} \mathrm{m} \mathrm{m}^{-1}\right]$} & Concentration of infective vector particles in permeate \\
\hline$h$ & {$[\mathrm{~m}]$} & Boundary layer thickness \\
\hline$h_{\max }$ & {$[\mathrm{m}]$} & Maximal boundary layer thickness \\
\hline$k$ & {$\left[\mathrm{~s} \mathrm{~m}^{4} \mathrm{~kg}^{-1}\right]$} & Initial flow constant described by Eq. 3 \\
\hline$k_{i}$ & {$\left[\mathrm{~s}^{-1}\right]$} & Inactivation constant of vector particles \\
\hline$k_{\mathrm{LFS}}$ & {$[-]$} & Fraction of LFS in the initial FCS content \\
\hline$K_{1}$ & {$\left[\mathrm{~s}^{-1}\right]$} & Constant describing layer resistance of Eq. 15 \\
\hline$K_{1}^{*}$ & {$\left[\mathrm{~kg} \mathrm{~s}^{-1} \mathrm{~m}^{-3}\right]$} & Constant describing layer resistance of Eq. 30 \\
\hline$K_{2}$ & {$\left[\mathrm{~kg} \mathrm{~m}^{-2} \mathrm{~s}^{-1}\right]$} & Constant describing the membrane resistance of Eq. 15 \\
\hline$K_{b}$ & {$\left[\mathrm{~s}^{-1}\right]$} & Complete blocking constant \\
\hline$K_{b 1}$ & {$\left[\mathrm{~s} \mathrm{~m} \mathrm{~kg}{ }^{-1}\right]$} & Complete blocking constant described by Eq. 3 and Eq. 4 \\
\hline$K_{c}$ & {$\left[\mathrm{~s} \mathrm{~m}^{-6}\right]$} & Cake filtration constant of Eq. 7 \\
\hline$K_{c 2}$ & {$\left[\mathrm{~kg} \mathrm{~m}^{-3}\right]$} & Cake filtration constant of Eq. 9 \\
\hline$K_{c 2^{*}}$ & {$\left[\mathrm{~kg} \mathrm{~s}^{-1} \mathrm{~m}^{-7}\right]$} & Constant of Eq. 10 \\
\hline$K_{c 3^{*}}$ & {$\left[\mathrm{~kg} \mathrm{~s}^{-2} \mathrm{~m}^{-4}\right]$} & Constant of Eq. 10 \\
\hline$K_{i b}$ & {$\left[\mathrm{~m} \mathrm{~s} \mathrm{~kg}^{-1}\right]$} & Intermediate blocking constant of Eq. 5 \\
\hline$K_{s b}$ & {$\left[\mathrm{~m}^{-3}\right]$} & Intermediate blocking constant of Eq. 6 \\
\hline$m$ & {$\left[\mathrm{~kg} \mathrm{~m}^{-2}\right]$} & Area specific layer mass \\
\hline$m_{\max }$ & {$\left[\mathrm{kg} \mathrm{m}^{-2}\right]$} & Maximal area specific layer mass \\
\hline$m_{R}$ & {$[\mathrm{~kg}]$} & Amount of LFS in the retentate \\
\hline$n_{A V_{P}}$ & [cfu] & Amount of infective units of retroviral vector in permeate \\
\hline
\end{tabular}




$\begin{array}{lll}n_{A V_{R}} & {[\mathrm{cfu}]} & \text { Amount of infective units of retroviral vector in retentate } \\ n_{I V R+P} & {[\mathrm{cfu}]} & \text { Amount of inactive vector in retentate and permeate } \\ Q & {\left[\mathrm{~m}^{3} \mathrm{~s}^{-1}\right]} & \text { Transmembrane flow } \\ Q_{0} & {\left[\mathrm{~m}^{3} \mathrm{~s}^{-1}\right]} & \text { Initial transmembrane flow } \\ Q_{L F S<-m e m} & {\left[\mathrm{~m}^{3} \mathrm{~s}^{-1}\right]} & \text { Flow of LFS from the mebrane } \\ Q_{L F S->m e m} & {\left[\mathrm{~m}^{3} \mathrm{~s}^{-1}\right]} & \text { Flow of LFS to the mebrane } \\ R & {[-]} & \text { Retention of vector particles } \\ R_{M} & {\left[\mathrm{~m}^{-1}\right]} & \text { Resistance of the membrane } \\ R_{M_{0}} & {\left[\mathrm{~m}^{-1}\right]} & \text { Initial resistance of the membrane } \\ R_{M_{c}} & {\left[\mathrm{~m}^{-1}\right]} & \text { Layer resistance of the membrane } \\ S & {\left[\mathrm{~kg} \mathrm{~m}^{-5} \mathrm{~s}^{-1}\right]} & \text { Cake erosion of Eq. } 9 \\ t & {[\mathrm{~s}]^{2}} & \text { Filtration time } \\ t_{1} & {[\mathrm{~s}]} & \text { Time when maximum of layer mass is reached } \\ \mathrm{V}_{\mathrm{P}} & {\left[\mathrm{m}^{3}\right]} & \text { Permeate Volume } \\ \mathrm{V}_{\mathrm{R}} & {\left[\mathrm{m}^{3}\right]} & \text { Retentate Volume } \\ \alpha & {\left[\mathrm{m} \mathrm{kg}^{-1}\right]} & \text { Layer or cake specific resistance } \\ \alpha P & {\left[\mathrm{~N} \mathrm{~m}^{-2}\right]} & \text { Transmembrane pressure difference } \\ \mu & {\left[\mathrm{kg} \mathrm{m}^{-1} \mathrm{~s}^{-1}\right]} & \text { Viskosity of the fluid } \\ v_{T M} & {\left[\mathrm{~m} \mathrm{~s}^{-1}\right]} & \text { Transmembrane flow velocity } \\ v_{T M \text { max }} & {\left[\mathrm{m} \mathrm{s}^{-1}\right]} & \text { Maxiumum transmembrane flow velocity } \\ \rho_{L F S} & {\left[\mathrm{~kg} \mathrm{~m}^{3}\right]} & \text { Density of LFS } \\ \sigma & {\left[\mathrm{m}^{-1}\right]} & \text { Blocked area per unit filtrate volume } \\ & & \end{array}$

\section{Acknowledgment}

The authors thank Prof. Dr. Claus Cichutek (Paul Ehrlich Institut, Germany) for the use of their packaging cell line and appreciate the financial support received from the Hessische Technologie Stiftung GmbH and from the Deutscher Akademischer Austausch Dienst.

\section{References:}

[1] S.T Andrealis, C.M Roth, J.M Le Doux, J.R. Morgan and M.L Yarumush, Large-scale processing of recombinat retrovirus for gene therapy, J. Biotechnol. Prog, 15 (1999) 111 .

[2] G. Braas, P.F. Searle, N.K.H. Slater and A. Lyddiatt, Strategies for the isolation and purification of retroviral vectors for gene therapy, J Biosparation 6 (1996) 211-228

[3] J.C. Burns, T. Friedmann, W. Driever, M. Burrascano and J.-K. Yee, Vesicular stomatitis virus $\mathrm{G}$ glycoprotein pseudotyped retroviral vectors: concentration to a very high titre and efficient gene transfer into mammalian and non.mammalian cells, Proc. Natl. Acad. Sci. USA 90 (1993) 8033-8037. 
[4] T.M. Clayton, Cell products- viral gene therapy vectors, in R.E. Spier (Ed.), Encyclopedia of cell technology, Wiley \& Sons, Chichester, UK, 2000, pp. 441-457

[5] P.E. Cruz, D. Goncalves, J. Almeida, J. Moreira and M.J.T. Carrondo, Modeling retrovirus production for gene therapy. 2. Integrated optimization of bioreaction and downstream processing, J. Biotechnol. Prog., 16 (2000) 350-357.

[6] R.W. Field, D. Wu, J.A. Howell, B.B. Gupta, Critical flux concept for microfiltration fouling. J. Membrane Sci. 100 (1995) 259-272.

[7] J. Hermia, Constant Pressure Blocking Filtration Laws: Application to Power-Law Non-Newtonian Fluids. Trans. Inst. Chem. Eng. 60 (1982) 183-187.

[8] J. Ingham, I.J. Dunn, E. Heinzle and J.E. Prenosil, An Introduction to Modelling and Computer Simulation, Second Completely Revised Edition, Wiley-WCH, Weinheim, 2000 .

[9] J. Irving, E.H. Dunn, E. Heinzle, J. Ingham and J.E. Prenosil, Biological Reaction Engineering, Applications and Modelling with PC Simulation, VCH, Weinheim, 1992

[10] M. Kuiper, R.M. Sanches, J.A. Walford and N.K.H. Slater, Purification of a functional gene therapy vector derived from moloney murine leukaemia virus using membrane filtration and ceramic hydroxyapatite chromatography, J. Biotechnol. Bioeng., 80 (2002) 445-453.

[11] S.-G. Lee, S. Kim and P.K. Wong, Optimization of enviromental factors for the purification and handling of recombinante retroviruses, J. Appl. Microbiol. Biotechnol., 45 (1996) 477-483.

[12] R. Macey, G. Oster and T. Zahnley, Berkeley Madonna's User Guide Version 8.0, Berkeley, CA, 2000.

[13] D. Pan and C.B. Whitley, Closed hollow-fiber bioreactor, a new approach to retroviral vector production, J. Gene Med., 1 (1999) 433-440.

[14] S.K. Powell, M.A. Kaloss and A. Pinkstaff, Breeding of retroviruses by DNA shuffling for improved stability and processing yields, J. Nat. Biotechnol., 18 (2000) $1279-1282$.

[15] R. Rautenbach, Membranverfahren Grundlagen der Modul- und Anlagenauslegung, in R. Rautenbach, Ultrafiltration und Mirkrofilatrion, Springer, Heidelberg, Germany, 1997, pp. 224-225.

[16] B. Richmond, An Introduction of Systems Thinking, High Performance System Inc., Hanover, NH, 2001.

[17] S. Ripperger, Mikrofiltration mit Mebranen, in S. Ripperger, Die CrossflowMikrofiltration, VCH, Weinheim, Germany, 1992, p. 157. 
[18] J. Stitz, P. Muller, H. Merget-Millitzer and K. Cichutek, High-titer retroviral pseudotype vectors for specific targeting of human CD4-positive cells, J. Biogenic Amines, 14 (1998) 407-424 